\title{
Foreword-Plastic pollution: a short and impressive story
}

\author{
Loris Pietrelli ${ }^{1}\left[\right.$. Sandro Pignatti ${ }^{2} \cdot$ Maria Cristina Fossi ${ }^{3}$
}

Received: 15 October 2018 / Accepted: 20 October 2018 / Published online: 31 October 2018

(c) Accademia Nazionale dei Lincei 2018

Human activities are responsible for a major decline of biodiversity and one particular form of human impact constitutes a major threat to marine and freshwater environments: the pollution by plastic debris.

Plastics are synthetic polymers and, unfortunately their characteristics that make them suitable for the manufacture of a wide range of products, make plastics a widespread pollutant. Their durability means that plastics persist in the environment for many years and, therefore, fragmentation that produces microplastics over time can be expected: no solutions are available for this kind of pollution. Actually, it has been estimated that about 8 million metric tons of plastic are thrown into the oceans annually, clearly the main problem is the waste management.

The first scientific article regarding the plastic pollution into the sea appears in 1969 when the authors wrote that they found plastic items in the stomach of seabirds. Some years later (1972) appeared in the Science journal the evidence of the presence of microplastics in all floating samples collected in the Sargasso sea surface. The authors wrote that "the increasing production of plastics combined with present waste disposal practices, will probably lead to

This paper is the peer-reviewed version of a contribution selected among those presented at the Conference on Marine Litter held at Accademia dei Lincei, Rome on December 1, 2017, organized jointly with ENEA and Forum Plinianum.

Loris Pietrelli

loris.pietrelli@enea.it

Sandro Pignatti

sandro.pignatti@gmail.com

Maria Cristina Fossi

fossi@unisi.it

1 ENEA - SSPT, C.R. Casaccia, Via Anguillarese, 301, 00060 Rome, Italy

2 Accademia Nazionale dei Lincei, Via della Lungara, 10, 00165 Rome, Italy

3 Dip. Scienze Fisiche, della Terra e dell' ambiente, Università di Siena, via Banchi di Sotto 55, 53100 Siena, Italy greater concentrations on the sea surface". It happened just a few years after the great expansion of the plastic industry to which the discovery of the Ziegler-Natta catalysts contributed.

Today the plastic industry represents an important manufacturing sector and it is a key sources moving the economy forward. The amount of plastics produced annually strongly increase over few decades to 332 million tonnes in 2017 (Plastic Europe 2018). In spite of the recent economic crisis, the amount of plastic waste is growing year by years.

Actually, given the impacts of plastic litter, marine and freshwater ecosystems protection and management have become important political and societal issues in EU. However, effective environmental management requires a proper understanding of both, the cause of the plastics widespread, to reduce the impact, and the ecological implications, therefore, sound multidisciplinary research, scientific advice, education and public outreach needs.

In the last 10 years trends in the numbers of papers on the marine litter strongly increase and in particular microplastics have become the most studied subject. Following this trend, on 1st December 2017, at Accademia dei Lincei (Rome) a Symposium has been organized, together with ENEA and Forum Plinianum, under the title "Marine litter: from emergency to resource". The program of the symposium has been conceived as a review of the research activities made in Italy.

During the symposium discussions were held on the results of many research projects, all participants agree that any pollution control and management action today must take into consideration not only the plastic diffusion but also the proper waste management and the sensitivity of citizens because it plays a highly significant role.

\section{Plastic Pollution: a short chronology}

Plastic was considered, erroneously, inert and, therefore, its impact on the environment and on human health was underestimated. To highlight the path and the contradictions that have marked the phenomenon of the plastic diffusion in the 
last few decades, a brief chronology of events is reported below

1965: Plastic shopping bags technology was patented by Swedish company Celloplast

1969: Plastic items founds in the stomach of seabirds

1972: Reports published in Science about the diffusion of microplastic in the North Atlantic lead to more research into the prevalence of plastic on the seafloor and its impact on marine animals.

1979: Plastic grocery bags are introduced in the U.S.

1980: Woodbury, New Jersey becomes the first U.S. city to adopt a curb side recycling program following litter awareness-campaigns in the 1960s and 1970s.

1982: Safeway and Kroger, two of the biggest supermarket chains in the United States, switch to plastic bags replacing paper bags.

1990s: Widespread use of plastic microbeads in cosmetics begins.

1997: Charles Moore discovers the Great Pacific Garbage Patch, the world's largest collection of floating garbage, when sailing home to Los Angeles.
2002: Bangladesh becomes the first country to ban plastic bags after discovering they blocked drains during a severe flood.

2007: San Francisco becomes the first U.S. city to institute a plastic bag ban.

Marine Strategy Framework Directive adoption by EU

2008: A government study (National Toxicology Program) confirms that Bisphenol A, a filler used to manufacture plastics, may increase risks of early cancer, prostate issues and behavioural problems.

2014: The Netherlands becomes the first country to ban microbeads in cosmetics.

2017: Ocean Conference organized by United Nations.

2017: Kenya bans plastic bags, making it one the most recent of the more than two dozen countries that have sought to reduce plastic bag use through fees or bans.

2018: \#BeatPlasticPollution is chosen as the theme of World Environment Day, 